\title{
Significados atribuídos ao alimento por pacientes com Anorexia Nervosa e por mulheres jovens eutróficas
}

\author{
Marina Garcia Manochio, (DD I, ${ }^{\star}$ Manoel Antônio dos Santos, (D) II Élide Dezoti Valdanha-Ornelas, (DD II \\ José Ernesto dos Santos, (D) II William Dressler, (D) III Rosane Pilot Pessa (iD) II \\ ${ }^{I}$ Universidade de Franca, Franca, SP, Brasil

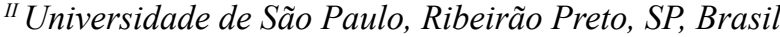 \\ III University of Alabama, Tuscaloosa, Alabama, EUA
}

\begin{abstract}
Resumo
Este estudo teve por objetivo identificar os significados atribuidos ao alimento por pacientes com Anorexia Nervosa (AN) e por jovens eutróficas sem sintomas de Transtornos Alimentares. Trata-se de um estudo qualitativo, comparativo e transversal. Foram entrevistadas 12 mulheres distribuidas em dois grupos focais: um composto por seis participantes com diagnóstico de AN, que frequentavam um serviço especializado (grupo de pacientes: GP) e outro, de comparação (GC), constituído por seis mulheres, eutróficas e sem sintomas de AN. Os encontros foram audiogravados e transcritos na íntegra. Para a análise de dados utilizou-se a técnica de análise de conteúdo temática e o marco teórico-conceitual da antropologia da alimentação, focalizando os significados do alimento e o valor simbólico das práticas alimentares. Verificou-se, em ambos os grupos, que os alimentos despertam uma gama de sentimentos paradoxais, variando desde prazer à repulsa, repúdio, nojo, culpa e medo. No GP, os significados são norteados pela importância capital atribuida ao conteúdo calórico em vez do valor nutricional dos alimentos. Para compreensão das práticas alimentares na anorexia, os profissionais devem estar atentos às determinações culturais, sociais e politicas que atravessam esse fenômeno, evitando a individualização do problema.
\end{abstract}

Palavras-chave: alimentos; hábitos alimentares; anorexia nervosa; transtornos da alimentação e da ingestão de alimentos

\section{Meanings assigned to food by patients with Anorexia Nervosa and by normal weight young women}

\begin{abstract}
This study aimed to identify the meanings assigned to food by patients with Anorexia Nervosa (AN) and by normal weight young women without symptoms of Eating Disorders. A qualitative, comparative and cross-sectional study was carried out. Twelve women were interviewed, divided into two focus groups: one composed of six participants diagnosed with AN attending a specialized service (patients group: $P G$ ), and the other group (comparison group: $C G$ ) was composed of six normal weight women without symptoms of AN. The meetings were audio recorded and transcribed verbatim. For data analysis, the thematic content analysis technique and the theoretical-conceptual framework of food anthropology were used, focusing on the meanings of food and the symbolic value of eating practices. It was found, in both groups, that food arouses a range of paradoxical feelings, ranging from pleasure to rejection, repudiation, disgust, guilt and fear. In the $P G$, the meanings are guided by the capital importance the participants assigned to the food caloric content, rather than nutritional value. Health professionals need to be sensitive to the verbal manifestations of AN patients in order to help them with the delicate balance between survival and denial of life. To understand eating practices in anorexia, professionals must be aware of the cultural, social and political determinations that go through this phenomenon, avoiding the individualization of the problem.
\end{abstract}

Keywords: food; food habits; anorexia nervosa; feeding and eating disorders.

$\mathrm{Na}$ abordagem biomédica, os transtornos alimentares (TAs) caracterizam um distúrbio persistente na alimentação e nos comportamentos relacionados ao comer, que resultam em significativa alteração na ingestão ou na absorção prejudicada de alimentos, acarretando prejuízos à saúde física e ao ajustamento psicossocial de adolescentes e adultos jovens (AMERICAN PSYCHIATRIC ASSOCIATION [APA], 2013). Admite-se que a etiologia dos TAs é multifatorial, de modo que diversos fatores atuariam como disparadores e mantenedores do quadro (COLUCCI, 2010; ROMANELLI, 2006).

\footnotetext{
^Endereço para correpondência: Universidade de Franca, Reitoria, Conselho Superior Universitário. Av. Dr. Armando Salles Oliveira, 201, Parque Universitário - Franca, SP - Brasil. CEP: 14404-600. Emails: mamanochio@yahoo. com.br, masantos@ffclrp.usp.br, elidevaldanha@usp.br, jedsanto@fmrp.usp.br, wdressle@as.ua.edu, rosane@eern.usp.b

Os dados completos dos autores encontram-se ao final do artigo.
}

A anorexia nervosa (AN) é um dos quadros clínicos mais proeminentes dentre os TAs, caracterizando-se por recusa sistemática em manter um peso compatível com a vida (LEONIDAS; SANTOS, 2012). O comportamento alimentar na AN reflete o receio mórbido de engordar, o que provoca intensas reações de ansiedade durante as refeições, cuidado excessivo quanto ao tamanho das porções a serem consumidas, mastigação lenta e combinações de alimentos pouco habituais (APA, 2013). Outras atitudes e hábitos alimentares disfuncionais são consequência da relação conflituosa com o alimento, mitos e crenças errôneas sobre nutrição e a natureza dos alimentos - que tendem a ser divididos, de modo maniqueísta, entre bons e maus, seguros e perigosos, permitidos e proibidos -, sentimentos confusos despertados pelo ato de se alimentar (repúdio, desejo, raiva, culpa, negação), além de pensamentos restritivos e obsessivos em relação 
à alimentação e seus possíveis efeitos no peso e no formato corporal (RIBEIRO, 2012). Esses elementos estão presentes e colorem a construção dos significados e sentidos emocionais do comer no indivíduo com diagnóstico de AN (LEONIDAS; SANTOS, 2017).

Estudos da área têm contribuído, ainda que involuntariamente, para construir ou reforçar uma representação estereotipada do indivíduo que sofre de anorexia como alguém que tem "dificuldades" em lidar com suas experiências emocionais e que vivencia altos níveis de ansiedade em seus vínculos familiares e relações interpessoais (ATTILI et al., 2018). Segundo uma visão relativamente cristalizada, a insegurança e imaturidade da personalidade podem ser percebidas no nível de distorção da autoimagem corporal, no campo das sensações paroxísticas, no desenvolvimento da identidade e na estruturação do pensamento (LEONIDAS; SANTOS, 2015).

A literatura frequentemente se vale de termos desqualificadores para se referir às experiências das pessoas com diagnóstico de anorexia. Conceitos desabonadores como incapacidade, distorção e disfuncionalidade são de uso corrente em vários estudos para nomear o que seria frequente ou que se supõe característico dessas participantes. $\mathrm{O}$ uso de termos como incapacidade, dificuldade, impossibilidade desqualificam o modo como essas pessoas lidam com a própria experiência, ou qualificam esse modo sob o registro do déficit, da desvantagem e da falta. Por exemplo, as mulheres com AN são muitas vezes rotuladas pela equipe médica como resistentes e refratárias a qualquer abordagem, ou pelos profissionais da psiquiatria ou psicologia como pacientes que têm dificuldades em lidar com suas experiências emocionais devido ao modo singular como se apropriam e vivenciam seus afetos.

Outro modo de colocar a experiência emocional das pacientes com $\mathrm{AN}$ em um registro negativo é afirmar que elas padecem de alexitimia, conceito da psicossomática que descreve a incapacidade de identificar as próprias emoções e a impossibilidade de descrevê-las e expressá-las de forma verbal, acarretando dificuldades em lidar com sentimentos e sensações corporais (LEONIDAS; SANTOS, 2020). Por isso, fariam uso maciço do mecanismo de denegação, mediante o qual recusam o alimento mesmo sentindo sua falta. De fato, ao contrário do que sugere o senso comum, pacientes com anorexia têm sensações físicas e psíquicas de fome.

A recusa alimentar é um comportamento desconcertante para os familiares e profissionais de saúde, especialmente pela tenacidade com que se mantém, por vezes ao longo de anos e décadas, a despeito dos efeitos deletérios à saúde e ao bem-estar da pessoa, levando-a ao extremo baixo peso. Os estudos que advogam a experiência anoréxica como evidência de psicopatologia apontam que a manutenção crônica dos sintomas tem consequências devastadoras para o organismo. Fraqueza, debilidade física, desidratação, descalcificação óssea, suscetibilidade a fraturas, distúrbios gástricos, baixa imunidade, entre outros agravos que cursam com o TA. Apesar da gravidade do comprometimento, a pessoa com anorexia não se percebe doente, o que aumenta a per- plexidade dos membros de seu círculo social, que não conseguem compreender como alguém pode se recusar voluntariamente a comer. Não ter consciência da própria vulnerabilidade e da gravidade do quadro clínico, negligenciando os riscos do engajamento prolongado em hábitos alimentares disfuncionais, acabaria por dificultar a procura e adesão ao tratamento (KLUMP, et al., 2009).

Os estudos são praticamente unânimes em afirmar que, por negarem de forma radical uma das necessidades mais básicas do ser humano - a de suprir sua demanda do alimento (entendido, pelo viés do lugar-comum e do pensamento essencialista, como "combustível da vida"), são pessoas que estão sempre às voltas com o risco iminente de morte. Nessa acepção, recusar-se deliberadamente a se alimentar e repudiar o próprio desejo de comer seriam experiências paradoxais, nas quais são confrontados os limites extremos da vida e da morte. Nesse sentido, a literatura entende que as pessoas com $\mathrm{AN}$ estão em contato íntimo e persistente com angústias de morte (COLUCCI, 2010; ROMANELLI, 2006). Essa dinâmica de funcionamento supostamente fragilizaria o indivíduo, especialmente diante de circunstâncias impostas pelos desafios das etapas de crise normativa e transição do ciclo vital, como ocorre na passagem para a vida adulta.

Ao reconhecermos essa situação de extrema vulnerabilidade, consideramos mais profícuo lançar nosso olhar analítico na direção dos processos culturais, que engendram os fenômenos contemporâneos que fazem do corpo a sede polimórfica do drama do existir (SANTOS et al, 2019). Entendemos que compreender o ato de comer exige desvelar esse fenômeno para além do campo estritamente biológico ou psicológico, penetrando no cerne cotidiano da cultura na qual o indivíduo constrói seus processos de subjetivação. A análise dos hábitos alimentares com enfoque antropológico apresenta diversas potencialidades, associadas à ênfase na dimensão simbólica presente na produção de alimentos e no preparo da comida (ROMANELLI, 2006). Nesse campo, uma representação sobre o hábito alimentar se configura como a percepção que a pessoa tem sobre determinado alimento (puro-impuro, light/diet-calórico, fraco-forte, leve-pesado, saudável-reimoso) e essa variedade de conceitos expressa o realismo das acepções existentes sobre o comer e as necessidades do corpo (FISCHLER, 2011). Ao adotar essa perspectiva analítica, podemos nos contrapor aos modelos clínicos que afirmam que pacientes com AN padecem de "alexitimia" ou que têm marcante dificuldade em lidar com seus sentimentos e sensações corporais. Consideramos mais profícuo pensar que, em vez de déficit ou transtorno psicopatológico, trata-se de "um outro modo" de lidar com os afetos e sensações corporais. Partimos do pressuposto de que não há um modo "melhor" ou "mais correto" de manejar as manifestações afetivas, e que não se pode afirmar que existiria um padrão ideal ou adequado de se lidar com as experiências emocionais.

Esse questionamento é relevante para evitar o risco de reproduzir um discurso normatizador que fixaria, a priori, os sentidos de adequação e inadequação, rendendo-se ao impulso normalizador que deseja regular as condutas hu- 
manas de acordo com um padrão arbitrariamente instituído como ideal e desejável. Na perspectiva que adotamos neste estudo, não há uma medida universal que permita a comparação de condutas, da mesma maneira que, para Canguilhem (2009), não há uma diferença fixa e estática entre a norma e seu desvio. Consideramos que as formas singulares de viver as emoções, independentemente de qualquer pré-julgamento, devem ser validadas porque são vivências emocionais descritas pelas participantes, sobre as quais podemos pensar que são "adequadas" "do ponto de vista de suas vivências". Além disso, quem de nós não enfrenta as chamadas "dificuldades emocionais" em diversas circunstâncias desafiadoras da vida?

$\mathrm{Na}$ direção inversa, nos estudos das experiências subjetivas de pessoas com TAs ainda prevalece um tipo de leitura psicológica que muitas vezes desqualifica e patologiza suas condutas. Essa postura tem sido bastante questionada contemporaneamente, pois evidencia as frágeis bases teórico-epistemológicas que balizam o olhar avaliador e classificador do expert, o "especialista" que se coloca como aquele que pontificará o que é ou não normal, adequado, equilibrado, legítimo, sensato, verdadeiro (SOUZA; SANTOS, 2013a, 2013b). Em uma perspectiva não patologizante, a evitação do afeto e as defesas que criam barreiras que dificultam o contato com as próprias emoções podem ser vistas não como evidência de falta, incapacidade ou sintoma clínico, mas como parte intrínseca à própria experiência afetiva. Assim como não se entra em contato direto com o próprio corpo, também não se tem acesso direto ànazs próprias emoções.

O juízo psicológico ou psicopatológico sobre o que se passa no universo anoréxico, presente em grande parte dos estudos da área (MIRANDA, 2004; VALDANHA et al., 2014; LEONIDAS et al., 2019; LEONIDAS; SANTOS, 2020), pode e necessita ser colocado em suspensão, para não se recair naquilo que Canguilhem (2009) chamou a atenção ao apontar os perigos da normalização da vida produzida pelo setor saúde como dispositivo social. O conceito instigante de normatividade vital emergiu na crítica desse autor ao modelo biomédico de saúde. Para ele, a normatividade vital é predominante nas ciências médicas e também se ramifica e é reproduzida na Psicologia. Para Canguilhem, uma experiência de adoecimento vivenciada de forma patológica por uma pessoa que pertence a um determinado contexto pode significar, para outra, que vive em outro contexto, uma oportunidade para produção de novas normatividades. Assim, seguindo os rastros desse raciocínio e levando-o às últimas consequências, pode-se afirmar que, de modo surpreendente e singular, é na doença que o organismo pode encontrar a saúde.

Nas representações coletivas da cultura alimentar, a comensalidade ocupa lugar de destaque. O termo deriva do latim mensa, que significa conviver à mesa, e envolve não somente o padrão alimentar ou "o que" se come, mas, principalmente, "como" se come. Assim, a comensalidade deixou de ser considerada consequência de fenômenos biológicos ou ecológicos para se tornar um dos fatores estruturantes da organização social (FISCHLER, 2011). O acesso, as escolhas e o preparo dos alimentos compõem a comensalidade e implicam em dar registro de identidade ao consumidor, que responde à sua necessidade biológica e sociocultural. A comensalidade se situa no mesmo campo semântico do consumo. Esse campo está relacionado ao modo pelo qual indivíduos se situam perante suas necessidades de sustento e seu sistema de valores, atribuindo significados e desenvolvendo modos rotineiros de lidar com a comida (DIEZ-GARCIA, 2012).

Já na perspectiva biológica, a ingestão de alimentos em quantidade e qualidade adequadas, com diversidade e equilíbrio, define o conceito de alimentação saudável, que visa a promover o adequado funcionamento do organismo e a manutenção e promoção da saúde. A ingestão deve, ainda, ser planejada com alimentos de todos os tipos, de procedência segura e conhecida, a partir de guias alimentares propostos nas políticas públicas. Adotar uma alimentação saudável não é meramente questão de escolha individual, uma vez que muitos fatores de natureza física, psicológica, econômica, política, cultural ou social podem influenciar negativamente o padrão de alimentação das pessoas (BRASIL, 2014).

O estudo das linhas de compreensão desse fenômeno complexo sugere a importância de considerar a dimensão da construção dos significados. Nesse sentido, compreender o significado do alimento sob diferentes perspectivas - de pessoas que desenvolveram um TA grave e outras, sem alterações nas suas práticas alimentares - pode ampliar a abordagem clínica dos problemas relacionados ao comportamento alimentar, visto que os hábitos alimentares fazem parte de um sistema cultural repleto de símbolos, classificações e significados. Assim, nenhum alimento está livre de associações com os valores simbólicos atribuídos pela sociedade, já que o comportamento em relação à comida está ligado diretamente ao modo como a coletividade constrói significações em cada época. Nessa medida, entende-se que os significados atribuídos ao alimento é uma construção de todos os sujeitos e, como tal, reflete a identidade social de cada um (DIEZ-GARCIA, 2012).

Diante desses pressupostos, este estudo teve por objetivo identificar os significados atribuídos ao alimento por pacientes com AN e por mulheres eutróficas, sem sintomas de TAs.

\section{Método}

Foi realizado um estudo transversal, comparativo, de natureza qualitativa. A pesquisa teve início após aprovação do Comitê de Ética em Pesquisa com Seres Humanos da instituição (parecer $n^{\circ} 1409 / 2011$ ). Todos os aspectos contidos na Resolução ${ }^{\circ}$ 466/2012 do Conselho Nacional de Saúde foram respeitados para a garantia de proteção das voluntárias. Para preservar a identidade das participantes os nomes reais foram substituídos por fictícios.

Foi utilizada a técnica de estudo de caso exploratório (YIN, 2001), considerando que a investigação dos significados do alimento construídos por pacientes com anorexia ainda é um fenômeno pouco estudado no contexto brasileiro. Este estudo é um recorte de uma pesquisa mais ampla, realizada em três serviços especializados para tra- 
tamento de TAs localizados em hospitais universitários de diferentes regiões do Estado de São Paulo, cujo objetivo foi identificar a presença de um modelo cultural na alimentação (MANOCHIO-PINA et al., 2015).

Os critérios utilizados para a seleção dos serviços/ hospitais foram: tipo de clientela atendida (Sistema Único de Saúde), tipo de atividade desenvolvida pelo hospital (ensino, pesquisa e assistência), vínculo institucional (faculdades de medicina de universidades públicas) e localização (Estado de São Paulo). Com base nesses critérios, três serviços localizados em hospitais gerais e de grande porte foram selecionados para realização do estudo, todos vinculados a universidades públicas estaduais e localizados em centros urbanos de referência do interior do Estado e da capital. Para a presente pesquisa foi selecionado um dos três serviços, com base em um critério de seleção único: a proximidade e familiaridade dos pesquisadores com o campo.

Participaram do estudo mulheres jovens, que foram divididas em dois grupos: grupo de pacientes com diagnóstico de AN (GP) e grupo de comparação (GC), composto por mulheres que não apresentavam evidências sintomáticas de TAs. O GP foi formado por pacientes com AN em tratamento no Grupo de Assistência em Transtornos Alimentares do Hospital das Clínicas da Faculdade de Medicina de Ribeirão Preto (GRATA-HCFMRP USP), independentemente do estado nutricional e da idade. Essa amostra foi definida por conveniência. O critério de inclusão utilizado foi aceitar expressar e compartilhar, no contexto de grupo, suas opiniões, experiências e sentimentos. O GC foi composto por mulheres consideradas eutróficas do ponto de vista nutricional (WORLD HEALTH ORGANIZATION [WHO], 2006) e sem diagnóstico de transtornos, estudantes e funcionárias de uma instituição de ensino superior do interior de São Paulo. Os critérios de exclusão adotados para os grupos foram: mulheres em situação de gestação; que não apresentassem as condições mínimas necessárias para desempenhar a tarefa em grupo, tanto em termos cognitivos (indício de rebaixamento no nível intelectual, avaliado empiricamente), como clínicos (presença de quadro grave de doença orgânica ou psiquiátrica - neste último caso, exceto para o diagnóstico de AN no GP), ou ainda deficiência auditiva ou de comunicação que inviabilizassem a realização da entrevista em grupo). A ausência de psicopatologia nas integrantes do GC foi definida com base nos resultados do questionário Eating Attitudes Test - EAT-26 - escore inferior a 21 pontos (BIGHETTI et al., 2004).

A pesquisa de campo foi realizada no período de março de 2012 a março de 2014 e os grupos focais foram realizados entre fevereiro e março de 2014. Seguindo os critérios de inclusão definidos, foram convidadas 10 pacientes para a entrevista de grupo focal, dentre as 17 que frequentavam o serviço na ocasião. O mesmo convite foi feito para 10 estudantes e funcionárias da universidade que compuseram o GC. Aceitaram participar e compareceram na data agendada seis participantes em cada grupo. A média de idade foi semelhante $(\mathrm{GP}=26$ anos; $\mathrm{GC}=$ 24 anos), a pontuação do EAT-26 foi maior no GP (GP =
37,9; $\mathrm{GC}=12,3)$ e o IMC $\left(\mathrm{kg} / \mathrm{m}^{2}\right)$ evidenciou baixo peso no GP (em média, $\left.18,2 \mathrm{~kg} / \mathrm{m}^{2}\right)$ e eutrofia no GC $(21,5 \mathrm{~kg} /$ $\mathrm{m}^{2}$ ). As pacientes com AN (GP) estavam em tratamento por um período variável (entre seis meses e 20 anos), sendo que duas se encontravam em estado de franca recuperação, o que levou a equipe de saúde a considerar a possibilidade de programar a alta hospitalar.

O grupo focal do GP foi realizado em sala reservada no contexto do serviço e o do GC em uma sala de uma universidade privada. Todas as participantes permaneceram até o final do grupo focal, que teve, aproximadamente, uma hora de duração. $\mathrm{O}$ roteiro semiestruturado foi composto pelas seguintes questões norteadoras: $\mathrm{O}$ que o alimento representa para vocês? Que sentimentos/sensações vocês têm ao comer? Quando vocês estão com fome e planejando comer algum alimento, em qual alimento pensam? Por quê? O que é um alimento saudável para vocês? Podem me dar alguns exemplos?

Para análise dos dados, utilizou-se a técnica de análise de conteúdo temática (BARDIN, 2008), que consiste nos seguintes passos: pré-análise, exploração, avaliação e interpretação. Essa análise foi realizada de forma independente por dois pesquisadores, com alto nível de qualificação acadêmica (doutorado) e longa experiência na clínica dos TAs, que não haviam participado da coleta de dados. Para evitar vieses, analisaram o material às cegas, isto é, sem prévio conhecimento de quais relatos haviam sido obtidos no GP e no GC. Assim, as análises não foram realizadas separadamente com cada grupo. Após a classificação de cada pesquisador, eventuais divergências no julgamento foram dirimidas por consenso ou com o apoio de um terceiro avaliador. Apenas depois de estabelecido o sistema de categorias e subcategorias as falas foram identificadas como de participantes pertencentes a um grupo ou outro.

O marco teórico-conceitual que inspirou as análises e a interpretação dos resultados obtidos no presente estudo baseou-se nos aportes da antropologia da alimentação (CANESQUI; GARCIA, 2005; SANTOS, 2008).

As correntes de pensamento utilizadas para a compreensão do problema investigado permitiram focalizar os significados do alimento, bem como o valor simbólico das práticas alimentares, em sua complexidade biológica, emocional, social e cultural (ALVARENGA; PHILIPPI, 2011; DAMATTA, 1986; DIEZ-GARCIA, 2012; FERNANDES, 2006; MIRANDA, 2004; RIBEIRO, 2012; ROMANELLI, 2006).

\section{Resultados e Discussão}

Por meio da análise temática foram identificadas duas categorias e suas respectivas subcategorias: alimento (a fronteira entre vida e morte; sentimentos e sensações; escolhas alimentares) e alimentação saudável (equilíbrio; pobre em calorias). Os significados encontrados nas narrativas foram analisados à luz do referencial teórico adotado e serão apresentados a seguir. 


\section{Alimento}

As participantes de ambos os grupos relataram os significados e sentimentos despertados pelo alimento e discorreram sobre suas escolhas alimentares.

\section{A fronteira entre vida e morte}

Nessa subcategoria da categoria "alimento" foram agrupados os excertos de fala que se reportaram ao alimento como algo essencial à vida, mas que, ao mesmo tempo, pode levar à morte.

"É uma coisa boa, saudável, é fonte de energia, é fonte de vida. Mas antes de ele ser tudo isso pra mim, ele é uma tortura. Ele me tortura. Aí, depois, ele é bom, prazeroso e tal, mas antes ele é [...] ele não é meu amigo ” (Alexia, GP).

"Quando eu tava doente, o alimento para mim era um inimigo [...] eu não precisava comer. Tanto porque eu tinha medo [...] eu queria ser perfeita, queria desaparecer literalmente e eu via números, eu não via comida, eu via números, calorias" (Adriana, GP).

As participantes do GP equacionaram o alimento a um insumo que é de importância vital para a sobrevivência. Por outro lado, associaram-no à tortura, ao sofrimento e à morte, possibilidade não rara diante da gravidade da doença, mas que mesmo assim elas não admitem e rejeitam enfaticamente. Do ponto de vista de autores da área, esse fenômeno da recusa da alimentação reflete a negação de algo da experiência cotidiana que mantém a vida. A pessoa com AN sofreria por vivências profundas de desamparo, mas se esforçaria para negar qualquer tipo de sofrimento ou sensação de falta. Nessa chave interpretativa, Miranda (2004) salienta que os TAs evocam intensas emoções, o que nos parece contraditório com a tese de alexitmia defendida por outros pesquisadores do campo.

A mobilização emocional também afetaria os profissionais de saúde que cuidam das pessoas com AN, que estariam suscetíveis a altos níveis de estresse ao se depararem com a tenacidade com que essas pacientes se aferram a seus sintomas e também por estarem em contato com vivências angustiantes que bordejam a fronteira vida-morte. De fato, há razoável consenso na literatura de que a recusa alimentar e demais sintomas constituem um tema impactante e mobilizador de ansiedade por tangenciar uma área da experiência tão básica como a alimentação, que na visão essencialista e de senso comum seria o "combustível da vida", primordial para a continuidade das funções vitais. Essa concepção de vida, amparada no discurso biomédico (GANGUILHEM, 2009), permite pensar que os profissionais de saúde que atuam com os TAs estariam sendo frequentemente convidados a percorrerem cenários de morte e dor, sofrimento e ruínas, ódio e destrutividade (FERNANDES, 2006).

Esse entendimento também tem propiciado que se entronizem crenças como a de que, para a pessoa com diagnóstico de AN, o poder do alimento é superestimado e se impõe como uma força absoluta e poderosa, ora fascinante, ora mortífera (MIRANDA, 2004). Assim, alimentar-se tornar-se-ia uma ação torturante e, muitas vezes, um ato quase pecaminoso.
Quando se analisam os relatos produzidos pelas participantes do GC, o alimento também aparece relacionado à vida e à sobrevivência, porém a dimensão sombria e degradante está ausente das significações atribuídas pelas mulheres que não apresentavam sintomas de AN. Entendemos que tal representação revela linearidade de significado: comida é vida e alimento é sobrevivência (FERNANDES, 2006). Claro que essa diferença é esperada, todavia, os resultados deste estudo fornecem pistas que permitem esclarecer que existe um viés nas concepções interpretativas predominantes que tendem a negligenciar que pessoas com TAs não menosprezam o valor vital do alimento.

Na visão da antropologia da alimentação, considera-se que os significados atribuídos à alimentação são produzidos em meio a um complexo circuito social de trocas, no qual o alimento é produzido, processado, distribuído, preparado, cozido, temperado, consumido e saboreado e, nesse sistema de múltiplas transformações, estabelece identidade social. Todavia, são ainda recentes os estudos sobre as representações socioculturais e a dimensão simbólica dos alimentos e das comidas nas distintas camadas sociais e grupos populacionais do país (SANTOS, 2008; SANTOS et al., 2015).

\section{Sentimentos e sensações}

Foram identificados sentimentos e sensações relacionados ao alimento. A comida pode despertar tanto sensações prazerosas (positivas) como desprazerosas (negativas). Subjacentes aos relatos há um complexo sistema de valores, símbolos e significados associados à dimensão do comer, visto que a alimentação vai muito além da ingestão de nutrientes e não deve ser compreendida sob um enfoque meramente biológico. Essa dinâmica alimentar complexa, que transcende o valor nutricional do alimento, pôde ser observada nas participantes do GP, quando demarcam que o ato de comer está diretamente relacionado aos aspectos emocionais. As pacientes com AN tentam controlar racionalmente suas necessidades corporais se autoimpondo uma disciplina rígida e inflexível, por meio da adoção de dietas restritivas e comportamento ascético, o que implica em renúncia a todo tipo de prazer e regozijo que se pode encontrar na vida (FERNANDES, 2006).

\section{Positivos}

Essa subcategoria abarca o prazer proporcionado pelo contato com o sabor dos alimentos e a evocação de memórias alimentares da infância. Os chamados comfort foods (alimentos que estimulam boas memórias) proporcionam sensação de bem-estar às participantes. No GP, foi apontado como positivo o fato de a pessoa não sentir nojo dos alimentos, já que essa sensação ocorria anteriormente com elevada frequência.

Nos relatos obtidos, a sensação de prazer que os alimentos podem proporcionar foi mencionada com maior frequência pelo $\mathrm{GC}$, em momentos nos quais as participantes pareceram se permitir falar (e viver) as sensações prazerosas mais livremente. Para elas, alimento também serve como ponto de atração e agregação, pois permite reunir a família e os amigos em torno dele, o que evidencia 
que a alimentação nem de longe é um fenômeno exclusivamente da esfera biológica, uma vez que sofre a influência de aspectos emocionais, sociais, culturais e políticos.

'Eu quero comer por prazer mesmo, e tem aquela hora que eu quero resultado [...] estou com fome e preciso comer alguma coisa para me manter [...] eu gosto muito de comer também [risos]. Então, alimento pra mim é isso [...] oportunidade de reunir. Então, quando a gente faz uma comida muito gostosa, vai ficar com a família [...]. Eu acho assim, que alimento [...] de vez em quando vou dar uma lembrancinha para alguém e eu dou um doce, um bombom, por que eu acho que o alimento entra por dentro, é aquele abraço interno' (Cláudia, GC).

Participantes do GP também enfatizaram a importância da comensalidade: “Ah, também penso no prazer, como ir em um bom restaurante ou cozinhar alguma coisa para os amigos, para a família" (Aisha, GP). A singularidade encontrada no GP é que algumas das participantes verbalizaram que tentam sufocar as sensações de prazer com a culpa acachapante que sentem após terem relaxado a vigilância e ingerido determinados alimentos, mesmo que em pequenas quantidades. Vale lembrar que pacientes com AN na verdade não perdem a fome, mas tentam controlar intensamente seu apetite e percebem o ato de se alimentar como um indício de fraqueza pessoal da qual se envergonham; os estudos tendem a interpretar essa tenacidade da recusa alimentar como indício de que provavelmente há um temor mórbido de perder o controle e então ceder a um comportamento estereotipado de compulsão alimentar (VALDANHA et al., 2014).

\section{Negativos}

Foram elencados nessa subcategoria sentimentos de tristeza, ódio, culpa, nojo, repulsa, aversão, medo, repugnância e desespero:

"Toda vez que eu comia eu ficava triste [...] eu achava que não precisava desse alimento, que ia viver bem sem ele [...] não queria admitir que sentia prazer [...] medo" (Amarílis, GP).

"A minha relação era doentia. Não era uma relação saudável. Eaté hoje, assim [...] a comida, ela ainda está ligada muito ao emocional. Se eu fico triste, eu não como direito. Qualquer emoção que tenho, eu desconto na comida [...] Se eu estou nervosa [...] uma punição. Se eu estou triste [...] obrigação” (Adriana, GP).

"A maioria das vezes que eu como, eu sinto culpa [...] Acho que é mais emocional. O cheiro de comida incomoda. Não gosto de cheiro de comida. Acho estranho, porque, sei lá [...] a maioria das pessoas come, né? Come arroz, feijão, carne [...] come comida, né? Não sente nada dessas coisas, gosta de comer, tem prazer em comer. Minha mãe adora arroz, feijão, comida, sabe? Já eu... [...]” (Alexia, GP).

"Só sei que me incomoda quando eu não meço a comida do meu prato. Quando eu não meço [...] aí aquilo me incomoda, nossa, porque não sei o quanto eu estou comendo. Ou eu fico com culpa ou eu fico, tipo [...]. dane-se [...] eu fico mais com culpa, assim [...] Só que, quando está comendo, você está feliz, né? Mas depois que acaba, você fica [...] nossa: "não podia comer!'. Aí você tem que se distrair, né? Ver outra coisa" (Ana, GP).
"Peso na consciência. Depende do que eu como [...] Instantaneamente. Quando eu estou comendo, falo: "só mais um pouquinho, só mais um pedacinho”. Depois que passa, sinto não devia ter comido" (Carla, GC).

No GP, conforme esperado, verificou-se uma relação conflituosa com o alimento. As preocupações obsessivas com a alimentação ultrapassam os limites necessários à preservação da vida, já que acarretam graves prejuízos físicos, agravos psíquicos e sofrimento social (KLUMP et al., 2009). Os relatos reportam vivências ambivalentes, que para alguns autores seriam características do funcionamento psicopatológico resultante da grave distorção da imagem corporal encontrada nesses indivíduos (BEUMONT et al., 1990; ALVES et al., 2008; ALVARENGA; PHILIPPI, 2011; LEONIDAS et al., 2019). Algumas participantes referiram sentir incômodo com o cheiro e o gosto dos alimentos, e desconforto por não conseguirem estimar a quantidade de comida no prato, o que desencadeia sentimento de culpa, além da falta de percepção de fome e saciedade. Algumas desejaram não sentir nada ao invés de sentir ódio ou nojo dos alimentos. Outras relataram que se sentem humilhadas por não terem controle sobre os alimentos. Apesar de rejeitarem a comida, o tempo todo elas pensam, planejam e sofrem com e pelo alimento. É uma dinâmica de repúdio de algo que, paradoxalmente, torna-se onipresente e ocupa o centro da vida psíquica. Recusa do desejo que, não obstante, estará lá o tempo todo provocando, instigando, restaurando seu poder tantalizante.

Entre as participantes do GC foi registrada apenas a sensação de bem-estar associada à ingestão alimentar, à exceção de uma participante, que referiu sentir culpa quando ingere alimentos mais calóricos. No GP o alimento que as participantes elegem como menos calórico coincide com o mais prazeroso e saudável. Segundo a literatura, a restrição calórica é parte da estratégia utilizada para controlar o peso. O não comer estaria associado ao triunfo do controle onipotente. Assim, resistir tenazmente às tentações, à fome e à vontade de comer confere às pacientes uma sensação de poder, força e bem-estar (ALVARENGA; PHILIPPI, 2011).

\section{Escolhas alimentares}

Nessa subcategoria, as verbalizações referem-se à forma e aos critérios utilizados pelas participantes para fazerem suas escolhas alimentares, considerando aversões e desejos.

"Ah, eu fico pesquisando. Eu, tipo [...] não gosto de comer coisa que tenha muita gordura, que não seja, assim [...] leve. Que, tipo [...] eu sou assim, viciada em comer proteina. E tipo, à noite eu não gosto de comer muito carboidrato. Ah, essas coisas, eu sou cheia de regras. Não é pela preferência, às vezes, assim [...] eu faço um cardápio, assim... eu não estou a fim de comer isso, mas eu como forçado, entende? Não é pela preferência. Sou eu. Eu falo pra minha mente que é pra comer. Mas não é pelo gosto” (Ana, GP).

"É aquilo ali que vai me satisfazer. Não é uma questão de horário" (Cláudia, GC). 
“Acho que horário [...] Geralmente, no café da manhã é mais leve [...] Ai vai chegando perto do horário do almoço, vai me dando vontade de comer sal. Ai passa o almoço, você almoça e vai dando vontade de comer um docinho, $e$ assim vai" (Cora, GC).

A alimentação no GP é cercada de regras autoimpostas, mesmo que precisem forçar a ingestão alimentar ou se alimentem apenas quando finalmente percebem que estão passando mal devido ao jejum prolongado. As participantes com AN vivenciam sua relação com o alimento como um "vício", no sentido de "adição", pois mesmo com todas as tentativas obstinadas de restrição alimentar, não podem ficar sem o alimento. Por isso, a comida lhes desperta sensações e vivências ambivalentes de desejo e repulsa, fascínio e rechaço, prazer e sofrimento. Etimologicamente, a palavra adição provém do verbo latino "addicere", que significa entregar-se, render-se. Portanto, a relação que as pacientes com AN estabelecem com o alimento é de rendição, de capitulação.

No GC, as escolhas alimentares estão relacionadas primordialmente à busca de satisfação e bem-estar, ou aos horários e refeições. Assim, o sabor do alimento e o que desejam comer também determinam a escolha. Outros relatos desse grupo mostram a importância atribuída ao ato de se submeter a uma dieta restritiva em busca de um controle alimentar eficiente, como estratégia para evitar o ganho de peso. As escolhas estão direcionadas, muitas vezes, às necessidades biológicas, com opção por alimentos que podem fazê-las mais fortes ou restabelecer as necessidades de nutrientes essenciais, como sódio. Segundo Alvarenga e Koritar (2015), a escolha é definida como um processo mental de pensamento que envolve julgamento dos méritos das várias opções disponíveis e a seleção de uma delas para a ação.

\section{Alimentação saudável}

As participantes de ambos os grupos relataram a busca do equilíbrio e a restrição calórica como critérios que habitualmente utilizam para obter uma alimentação saudável.

\section{Equilíbrio}

Nessa subcategoria da categoria "alimentação saudável" foram encontradas contradições bem salientes em algumas falas.

"A gente precisa de tudo, todos os nutrientes [...] mas eu acho que tem alguma coisa que a gente tem que moderar [...] Tipo, a gente não precisa ficar comendo todo dia [...] quando tem vontade a gente pode comer, né?" (Amarílis, GP).

"Eu acho que o que a gente tem de carboidrato, proteina e lipídio, acho que todos os alimentos são saudáveis, tirando, assim [...] os fast foods, as coisas que foram inventadas, que não saem da natureza, da agricultura nem nada [...]" (Cláudia, GC).

De modo geral, segundo a percepção das participantes, alimentação saudável significa ingerir todos os alimentos, inclusive aqueles que eliciam mais diretamente a sensação de prazer. No GP, a noção de equilíbrio está associada à quantidade de alimentos que as participantes se permitem consumir, com ênfase no senso de controle absoluto da ingestão - basta recordar a expressão: "Eu falo pra minha mente que é pra comer" (Ana, GP). Para o GC, além de ter importante papel na promoção da saúde, a ingestão do alimento saudável também está relacionada a aspectos simbólicos, como apreciar um sabor especial e fruir o sentido gregário da alimentação, ao proporcionar, por meio da comensalidade, a sociabilidade em torno do ato de comer - por exemplo, em reuniões com amigos.

Com o crescente avanço científico e tecnológico obtido nas últimas décadas, a alimentação passou a ser uma prática cada vez mais regulada e disciplinada. A aceleração do processo de industrialização promoveu significativas mudanças nos hábitos alimentares da população, inspirando preocupação nas autoridades e gestores de saúde pública (BRASIL, 2014), uma vez que os padrões alimentares oferecem riscos se a alimentação não for adequada e equilibrada (DIEZ-GARCIA, 2012). Para as participantes com AN, o aspecto social da alimentação em geral se mostra prejudicado devido às dificuldades de comer na presença de outras pessoas, o que acentua a tendência ao isolamento familiar e social (LEONIDAS; SANTOS, 2014).

Na perspectiva biológica, o conceito de alimentação saudável refere-se à ingestão de alimentos em quantidade e qualidade adequadas, com diversidade e equilíbrio entre os grupos alimentares, a fim de promover um adequado funcionamento do organismo e a manutenção e promoção da saúde. Envolve, assim, a diminuição do consumo de alimentos industrializados e o incremento de víveres in natura, principalmente vegetais (verduras e legumes) e frutas. A dieta deve ser planejada com alimentos de todos os tipos, de procedência segura e conhecida, a partir de guias alimentares propostos nas políticas públicas. Visto dessa perspectiva biologizante, o "comer normal" é um comportamento flexível, que varia em resposta a emoções, disponibilidade de agenda, sensação de fome-saciedade e proximidade com o alimento (SATTER, 2007).

Canguilhem (2009) identifica a normalização como o primado fundamental do modelo biomédico. O conceito de "normatividade vital" proposto pelo autor é uma ferramenta conceitual útil para comprender a lógica de produção biológica, que não toma a norma como critério de valoração das formas de vida possíveis. Esse conceito advoga que não são as individualidades biológicas que se ajustam ou se afastam das normas, como habitualmente somos levados a pensar. Ao contrário, é a individualidade biológica, como potência de criação de novas formas vitais, que produz o processo de sua normatividade (NEVES; PORCARO; CURVO, 2017).

A tendência contemporânea é considerar a alimentação como um constructo complexo e relevante, e não algo associado a um ou outro alimento, pois nenhum por si só causa malefícios ou benefícios à saúde. Já o excesso ou falta constante de alguns nutrientes é prejudicial e pode comprometer o funcionamento do organismo. A maioria da população percebe os alimentos de maneira dicotômica (bons/permitidos versus ruins/proibidos), o que pode levar a episódios de exagero e, no limite, favorecer a compulsão alimentar (NITZKE; FREELAND-GRAVES, 
2007). A publicidade, por sua vez, apropria-se de fatos científicos para legitimar seus produtos e dotá-los de uma posição de destaque em uma hierarquia de prestígio social que permite categorizá-los como mais saudáveis e, assim, recomendáveis para a manutenção de boas condições de saúde. Essa valoração repercute na maneira como as pessoas se percebem e também pode ter reflexo nas práticas alimentares, uma vez que envolve noções sobre saúde e alimentação, sobre o que faz bem ou o que faz mal, ou aquilo que supostamente favorece uma vida longa ou contribui para precipitar uma morte prematura.

Essa valoração cultural introduz um signo que se torna indissociável do produto. Esse atributo intangível, uma vez assimilado como parte do valor simbólico do alimento, tem influência nas escolhas alimentares das pessoas (DIEZ-GARCIA, 2012). A nosso ver, esse entendimento deve ser visto com ressalvas, ou seja, como uma possibilidade de compreensão dentre outras. Há que se refletir sobre a exploração que tem sido feita pela televisão nos últimos anos, com a proliferação de programas de culinária e competições do tipo reality show em torno do preparo de pratos. Esse fenômeno pode ser visto como um claro subproduto do consumo de massa, travestido em práticas e conhecimentos relacionados com a arte culinária, mas que na verdade nada tem de gastronomia. Sem contar que se reforça a experiência paradoxal da incitação ao comer, simultaneamente à imposição da magreza e sua associação com certos padrões estéticos valorizados em nossa época (SANTOS et al., 2019).

Para alguns autores é imprescindível resgatar a legitimação do prazer, do bem-estar e do gosto envolvidos no processo de escolha alimentar. Tais autores defendem que comer de forma saudável não está relacionado apenas à manutenção da saúde, mas a um padrão de comportamento socialmente aceitável, que deve ser flexível e gerar satisfação (BEUMONT et al., 1990; SANTOS; DIEZ-GARCIA; LIOTINO-SANTOS, 2015). Consideramos essa posição um tanto quanto duvidosa, para não dizer moralista. Pensando junto com Canguilhem (2009), a normatividade vital associa determinados hábitos alimentares, como "comer de forma saudável", a um padrão de conduta socialmente aceitável. Essa moralização do ato de comer institui novas pautas de normalidade a serem seguidas por todos e propagadas pelos profissionais de saúde, estética e educação física.

Em uma compreensão psicanalítica, na AN o não comer parece estar associado à tentativa de obter controle mental absoluto sobre as necessidades corporais, e é por isso que o ato de resistir tenazmente às tentações, às manifestações orgânicas e psíquicas da fome e à vontade de comer confere uma vivência de triunfo e poder ilimitado aos pacientes (MIRANDA, 2004; FERNANDES, 2006; COLUCCI, 2010). No entanto, quanto mais restringem sua ingesta alimentar (ou seja, quanto menos comem), mais pensam, de forma fixa e estereotipada, em comida, calorias e dietas (SANTOS, 2006). Os sentimentos em relação à alimentação também se mostram comprometidos, pois as pessoas estão sempre tentando comer menos ou perseverar em jejuns prolongados ou infinitas dietas.
Também costumam relatar raiva ao perceberem que, sim, também são acometidas pela sensação de fome. Mas o que prevalece, geralmente, é que se sentem incompetentes em relação à gestão dos alimentos e passam a expressar repugnância por eles. Acentuam suas vivências distorcidas da comida, do ato de comer e do corpo. Não reconhecem que têm dificuldades com o alimento e acreditam que o problema é a existência dos víveres; sem eles o mundo seria um lugar melhor e perfeito (ALVARENGA; PHILIPPI, 2011). Ficam girando em falso, paralisadas, em um círculo vicioso que perpetua seus sintomas, encalacradas entre a busca da autonomia e a cooptação por um ideal inalcançável de perfeição corporal (SANTOS, 2006).

Tanto para os indivíduos com AN quanto para os obesos, a inquietante liberdade que as pessoas desfrutam na atual sociedade para consumir larga e abundantemente gera padrões alimentares que refletem a "crise" da alimentação na contemporaneidade. Crise no sentido de que, em meio a tantas prescrições, que contrapõem fartura e privação de alimentos, já não se sabe o que se deve e o que não se deve comer (SANTOS et al., 2019).

Medeiros e Galeno (2013) consideram que é importante incentivar o comer saudável, mas de forma flexível e individual, atrelado à dimensão do prazer, levando em consideração as questões emocionais, sociais, culturais e simbólicas que permeiam os significados construídos para os alimentos. O papel da equipe deveria ser não o de pensar apenas no que significa a alimentação para as pessoas, fornecendo-lhes fórmulas prontas como resposta às suas angústias e questionamentos, mas pensar a alimentação "com as" pessoas, ajudando-as a lidar com a avalanche de informações com as quais se deparam na era contemporânea, para que, assim, selecionando e organizando os conhecimentos absorvidos possam constituir-se como sujeitos de suas escolhas (ALVES et al., 2008).

\section{Restrita em calorias}

Nessa subcategoria, o significante "calorias" emerge como o elemento organizador para que o alimento possa ser classificado como saudável.

"A nutricionista fala que a gente pode comer de tudo. Tudo que a gente quer, que a gente gosta de comer, né? Mas tem que comer tudo certo, comer aos poucos, não é tudo de uma vez. Não é todo dia comer alimentos muito calóricos. [...] Mas a gente não consegue. Porque nem é saudável, nem é não saudável. [...] Muita coisa saudável tem caloria baixa" (Alexia, GP).

"Eu penso mais em verdura, em legume. É [...] coisas integrais. Mais nisso, sabe? Menos fritura, menos refrigerante, menos doce. Na verdade, eu penso em zerar quando eu falo que vou comer saudável, tipo: nada de fritura, nada de doce, nada de refrigerante. É meio radical" (Adriana, GP).

“Eu penso em calorias” (Carla, GC).

"Não ter agrotóxicos, não ter gordura trans, sabe aquelas coiseradas?" (Cora, GC).

A maioria das participantes do GP associou o conceito de saúde com o conteúdo calórico dos alimentos, apesar de relatarem compreender a definição teórica 
de alimento saudável. No GC, apenas uma participante mencionou que o teor calórico dos alimentos é determinante na sua conceituação de alimentação saudável. Os relatos das mulheres com AN sugerem que elas são adeptas de um tipo de pensamento conhecido como "tudo-ou-nada", que é reportado como frequente no contexto de vida das pessoas com $\mathrm{AN}$ e que predispõe à adoção de atitudes e práticas de restrição alimentar. Nas palavras de Adriana (GP), uma atitude de moderação na ingestão de alguns alimentos (“menos...") acaba por se converter em uma experiência de eliminação sumária desses itens de seu cardápio ("nada de..."). Assim, a recomendação de comer " "menos' fritura, 'menos' refrigerante, 'menos' doce" acaba se transformando com facilidade no mantra pessoal: "'nada' de fritura, 'nada' de doce, 'nada' de refrigerante". Então, da restrição ao jejum, do "menos" ao "nada", é apenas um passo.

As atitudes alimentares das mulheres com AN refletem uma postura de rigidez exacerbada na ingestão alimentar, com a radicalização da restrição do consumo, principalmente de gorduras e carboidratos. Essas participantes consideraram poucos itens alimentares como saudáveis - frutas, verduras, leite e seus derivados - e que podem ser ingeridos com frequência, ainda que mínima. Outros autores já observaram que há forte tendência de os pacientes com TAs optarem pelo consumo de pequenas quantidades desses alimentos, buscando deliberadamente induzir a manutenção ou perda acentuada de peso. Coincidentemente, tais alimentos são também considerados como mais saudáveis (MEDEIROS; GALENO, 2013).

\section{Considerações finais}

Os resultados destacados no presente estudo revelam que os alimentos são significados pelas participantes com AN por meio de diferentes representações coletivas. Os significados construídos coletivamente são apropriados e subjetivados de forma peculiar. Muitas vezes são permeados por sentimentos contraditórios de sobrevivência e ao mesmo tempo impossibilidade de assegurar algumas das condições mínimas para se viver. As atitudes alimentares são orientadas pelo conteúdo calórico dos alimentos, buscando abrandar a carga terrorífica que eles inspiram nessas pessoas. As sensações experimentadas diante da comida incluem desde o desejo e prazer suscitados pelo alimento até a repulsa e nojo ostensivo, medo da comida, culpa e aversão alimentar. O prazer que eventualmente pode ser auferido com a alimentação é duramente criticado e condenado pelas próprias participantes.

Essa singularidade da experiência anoréxica tem sido interpretada como expressão de uma suposta psicopatologia, que inclui distúrbios na esfera do pensar e distorção na imagem corporal. Essa maneira de significar os fenômenos complexos que se manifestam na anorexia coloca o problema como da ordem de um profundo desajustamento vivenciado em relação às normas que regulam o mundo familiar, social e cultural. Mas também podemos pensar se não é esse ambiente e suas normas que estão desajustados. Por essa razão é preciso ter cautela para não individualizar a questão, como o faz a visão psicopatologizante, o que reduz o horizonte de compreensão, perdendo de vista sua multidimensionalidade.

Para o entendimento das representações culturalmente construídas sobre a comida, desejos, hábitos, atitudes e práticas alimentares, torna-se capital buscar conteúdos de disciplinas das ciências humanas que permitam ampliar o referencial teórico para uma dietética compreensiva e assimilar as narrativas ou discursos das pessoas. Isso é necessário, sobretudo, para abranger a complexidade dos enunciados sobre o comer e estimular a produção de um conhecimento que se mostre sensível às nuances e sutilezas que atravessam a relação estabelecida pelo "paciente" - aqui entendido como aquele que recebe o tratamento - com o profissional de saúde.

O discurso das pacientes veicula interpretações elaboradas sobre o comer e o corpo que influenciam suas atitudes, impactam suas decisões e deflagram tensões e contradições que são vivenciadas em sua conduta alimentar. É na (e pela) linguagem que o indivíduo se insere em sua comunidade e procura articular-se com o mundo social. As graves distorções e disfunções do comportamento alimentar, como se pode perceber na radicalidade dos sintomas da AN, expressam, na chave da intersubjetividade, as experiências e sentimentos de deslocamento do sujeito no mundo contemporâneo. Mas há que se considerar também que é esse mundo fraturado que produz ativamente o desajustamento do sujeito, por meio da crescente desfiliação e despertencimento, das rupturas identitárias, da supressão dos laços sociais, do apartheid da população desfavorecida, da mercantilização das relações e da fetichização das necessidades pulsionais, que também impactam no desconforto vivenciado no cotidiano alimentar. Mesmo que se possa admitir que no sintoma reside de fato uma "recusa ao mundo", estando nele inseridos o alimento e a própria paciente, não se pode separar tal experiência do mundo, com suas determinações de gênero, classe social, culto ao corpo, ideal de magreza, individualismo, incitamento ao gozo e imediatismo do prazer.

No setor saúde, por força da onda normalizadora que o discurso biomédico impõe, há uma ênfase quase absoluta na necessidade de mudança de hábitos nocivos de saúde. Parece que, nesse caso, não se trata tanto de nos empenharmos na obtenção de uma mudança de hábitos alimentares, mas de termos uma compreensão mais abrangente dos vetores de força que levam a tal situação e de como cuidar clinicamente, existencialmente e politicamente no âmbito da coletividade. Assim, conhecer os significados, valores, crenças e outros aspectos culturais que pontuam o universo simbólico da alimentação pode inspirar práticas transformadoras.

Espera-se que os resultados deste estudo possam contribuir para a aquisição de novas estratégias de cuidado e aprimoramento das habilidades de escuta por parte dos profissionais de saúde que compõem a equipe multiprofissional, que devem estar atentos à diversidade de significações atribuídas ao alimento no campo social e dos TAs. É preciso conhecer os recursos que podem ser utilizados como ferramentas terapêuticas, proporcionando estraté- 
gias que contribuam para a otimização do acolhimento e do cuidado. Por exemplo, é imperioso que os profissionais estejam atentos à necessidade de contextualização do fenômeno aqui estudado, no que se se refere às determinações (a que todos estamos submetidos) que com ele podem guardar relação, como o culto à imagem e ao corpo esquálido, a exacerbação do individualismo e dos aspectos sensoriais da experiência, as questões de gênero e as exigências estéticas que se materializam em padrões inalcançáveis, sobretudo para as mulheres, entre outros fatores contextuais. São aspectos culturais, sociais e políticos que precisam ser levados em conta na formulação de políticas públicas e no planejamento de ações de intervenção.

Nos meandros por entre o corpo, o comer e a comida atravessam aspectos culturais, sociais e políticos que caracterizam o mundo contemporâneo e que precisam ser levados em consideração para a compreensão das práticas alimentares e corporais.

\section{Informações sobre os autores:}

Marina Garcia Manochio-Pina

(iD) https://orcid.org/0000-0002-7851-0508

(3) http://lattes.cnpq.br/4004198585216269

Vice-coordenadora e docente do Programa de Pós-Graduação em Promoção de Saúde (mestrado e doutorado) e do curso de Nutrição da Universidade de Franca - UNIFRAN. Graduação em Nutrição pela Universidade de Franca (2005). Mestrado em Saúde Pública pela Escola de Enfermagem de Ribeirão Preto, Universidade de São Paulo - EERP-USP (2009). Doutorado em Ciências pela EERPUSP (2014). Pós-Doutorado pelo Departamento de Ciências da Saúde da Faculdade de Medicina de Ribeirão Preto, Universidade de São Paulo - FFCLRP-USP (em andamento). Membro do colegiado do curso de Promoção de Saúde e do curso de Nutrição, atuando nas linhas de pesquisa Políticas e Práticas em Promoção da Saúde e Ambientes, Tecnologias e Sustentabilidade em Promoção da Saúde. Presidente do Comitê de Inserção Social (CIS) da UNIFRAN. Coordenadora da Clínica de Nutrição e do Núcleo de Estudos e Assistência em Transtornos Alimentares e Obesidade (NEOTA), UNIFRAN. Membro do Grupo de Assistência em Transtornos Alimentares (GRATA) do Hospital das Clínicas da Faculdade de Medicina de Ribeirão Preto (HCFMRP USP). Líder do Grupo de Pesquisa cadastrado no Diretório do CNPq: Núcleo de Estudos do Comportamento Alimentar e Promoção da Saúde/ NECAPSq. Membro do Grupo de Pesquisa Núcleo de Estudos e Pesquisas em Promoção da Saúde (NEP-PS).

Manoel Antônio dos Santos

(iD) http://orcid.org/0000-0001-8214-7767

(9) http://lattes.cnpq.br/1632921993169300

Professor Titular da Faculdade de Filosofia, Ciências e Letras de Ribeirão Preto da Universidade de São Paulo (FFCLRPUSP), desde 1987. Professor do Programa de Pós-Graduação em Psicologia da FFCLRP-USP. Graduação em Psicologia. Mestrado em Psicologia Clínica e Doutorado em Psicologia Clínica pelo Instituto de Psicologia da Universidade de São Paulo. Livredocência em Psicoterapia Psicanalítica pela FFCLRP-USP. Bolsista de Produtividade em Pesquisa do CNPq, PQ-1A. Membro Titular da Academia Paulista de Psicologia. Coordenador do Laboratório de Ensino e Pesquisa em Psicologia da Saúde (LEPPS-FFCLRPUSP/CNPq) e do Grupo de Ação e Pesquisa em Diversidade Sexual e de Gênero (VIDEVERSO-FFCLRP-USP). Coordenador da equipe de Psicologia do Grupo de Assistência em Transtornos Alimentares (GRATA) do Hospital das Clínicas da Faculdade de Medicina de Ribeirão Preto (HC-FMRP-USP).

\section{Élide Dezoti Valdanha-Ornelas \\ (iD) https://orcid.org/0000-0002-0735-9660 \\ (3) http://lattes.cnpq.br/0473281974094482}

Psicóloga e Bacharel Especial em Pesquisa pela Faculdade de Filosofia, Ciências e Letras de Ribeirão Preto da Universidade de São Paulo - FFCLRP-USP. Mestre pelo Programa de Pós-Graduação em Psicologia da FFCLRP -USP. Doutora pela École Doctorale Recherches en Psychanalyse et Psychopathologie, Université ParisDiderot (Paris 7 - Université Sorbonne Paris Cité) e pelo Programa de Pós-Graduação em Psicologia da FFCLRP-USP. Membro do Laboratório de Ensino e Pesquisa em Psicologia da Saúde (LEPPSFFCLRP-USP/CNPq). Membro do Grupo de Assistência em Transtornos Alimentares (GRATA) do Hospital das Clínicas da Faculdade de Medicina de Ribeirão Preto (HC-FMRP-USP).

\section{José Ernesto dos Santos \\ (iD) https://orcid.org/0000-0003-3269-1582 \\ (3) http://lattes.cnpq.br/5427796651259253}

Professor Associado (aposentado) da Faculdade de Medicina de Ribeirão Preto (FMRP-USP). Graduação em Medicina pela Faculdade de Medicina de Ribeirão Preto (1970). Mestrado (1974), doutorado (1978) e livre docência (1982) em Clínica Médica pela Faculdade de Medicina de Ribeirão Preto (1974). Pos-doctoral Fellow da Universidade do Alabama-Birmingham. Atualmente é coordenador do Curso Médico da Universidade Estácio em Ribeirão Preto e Professor Sênior da Faculdade de Medicina de Ribeirão Preto. Foi coordenador do Grupo de Assistência em Transtornos Alimentares (GRATA) do Hospital das Clínicas da Faculdade de Medicina de Ribeirão Preto (HC-FMRP-USP). Tem experiência na área de Medicina, com ênfase em hiperlipemias, obesidade e transtornos alimentares.

William Winner Dressler

(iD) https://orcid.org/0000-0001-7892-2652

$\mathcal{A}$ http://bdressler.people.ua.edu/about-bill-dressler.html

Professor Emeritus, Department of Anthropology, University of Alabama, USA. Doutorado pela Universidade de Connecticut, USA (1978). Além de lecionar antropologia, atuou na Faculdade de Medicina da Universidade do Alabama-Tuscaloosa e da Escola de Serviço Social. Sua linha de pesquisa aborda a relação entre cultura e saúde. O estudo mais recente enfatiza conceitos e métodos para examinar os efeitos na saúde de esforços individuais para alcançar objetivos e aspirações culturalmente definidos. No Brasil, dedicou-se a quatro grandes projetos financiados em saúde nos últimos 30 anos.

\section{Rosane Pilot Pessa \\ (iD) https://orcid.org/0000-0002-6301-6830 \\ (9) http://lattes.cnpq.br/5372275432577010}

Professora Associada 2 do Departamento de Enfermagem MaternoInfantil e Saúde Pública da Escola de Enfermagem de Ribeirão Preto da Universidade de São Paulo (EERP-USP), desde 1997. Graduação em Nutrição pela Pontifícia Universidade Católica de Campinas - PUCAMP (1984). Mestrado em Psicobiologia (Faculdade de Filosofia, Ciências e Letras de Ribeirão Preto, Universidade de São Paulo, 1995). Doutorado em Saúde Mental (Faculdade de Medicina de Ribeirão Preto, Universidade de São Paulo, 1999) e Pós-Doutorado em Antropologia (The University of Alabama, USA, 2019). Desenvolve atividades de ensino de graduação e pós-graduação, pesquisa e extensão de serviços à comunidade. É coordenadora do Programa de Educação Alimentar do Campus da USP de Ribeirão Preto (PRAUSP) e Vice-Coordenadora do Grupo de Assistência em Transtornos Alimentares (GRATA) do Hospital das Clínicas da Faculdade de Medicina de Ribeirão Preto (FFCLRP-USP). Tem experiência na área de Nutrição em Saúde Pública e Nutrição Clínica, atuando principalmente junto aos temas transtornos alimentares (anorexia nervosa e bulimia nervosa) e obesidade. 


\section{Contribuições dos autores:}

Todos os autores colaboraram ao longo do processo, desde a elaboração até a revisão final do manuscrito. Os autores aprovaram o manuscrito final para publicação.

\section{Como citar este artigo:}

\section{ABNT}

MANOCHIO, Marina Garcia et al. Significados atribuídos ao alimento por pacientes com Anorexia Nervosa e por mulheres jovens eutróficas. Fractal: Revista de Psicologia, Niterói, v. 32 , n. 2, p. 120-131, maio/ago. 2020. https://doi.org/10.22409/19840292/v32i2/5626

\section{APA}

Manochio, M. G., Santos, M. A., Valdanha-Ornelas, É. D., Santos, J. E., Dressler, W., \& Pessa, R. P. (2020, Maio/Agosto). Significados atribuídos ao alimento por pacientes com Anorexia Nervosa e por mulheres jovens eutróficas. Fractal: Revista de Psicologia, 32(2), 120-131. doi: https://doi.org/10.22409/1984-0292/v32i2/5626

\section{Copyright}

Copyright (C) 2020 Manochio, M. G. et al. Este é um artigo em acesso aberto distribuído nos termos da Licença Creative Commons Atribuição que permite o uso irrestrito, a distribuição e reprodução em qualquer meio desde que o artigo original seja devidamente citado.

Copyright (C) 2020 Manochio, M. G. et al. This is an Open Access article distributed under the terms of the Creative Commons Attribution License, which permits unrestricted use, distribution, and reproduction in any medium, provided the original article is properly cited.

\section{Referências}

ALVARENGA, Marle dos Santos; PHILIPPI, Sonia Tucunduva. Estrutura, padrão, consumo e atitude alimentar: conceitos e aplicações nos transtornos alimentares. In: ALVARENGA, Marle dos Santos; SCAGLIUSI, Fernanda Baeza; PHILIPPI, Sonia Tucunduva (Org.). Nutrição e transtornos alimentares: avaliação e tratamento. Barueri: Manole, 2011. p. 17-36.

ALVARENGA, Marle dos Santos; KORITAR, Priscila. Atitude e comportamento alimentar: determinantes de escolhas e consumo. In: ALVARENGA, Marle dos Santos et al. (Org.) Nutrição comportamental. São Paulo: Manole, 2015. p. 23-50 .

ALVES, Emilaura et al. Prevalência de sintomas de anorexia nervosa e insatisfação com a imagem corporal em adolescentes do sexo feminino do município de Florianópolis, Santa Catarina, Brasil. Cadernos de Saúde Pública, Rio de Janeiro, v. 24, n. 3, p. 503-512, mar. 2008. https://doi.org/10.1590/S0102311X2008000300004

AMERICAN PSYCHIATRIC ASSOCIATION (APA). Diagnostic and statistical manual of mental disorders. 5. ed. Arlington, VA: American Psychiatric Association, 2013.

ATTILI, Grazia et al. High anxiety attachment in eating disorders: intergenerational transmission by mothers and fathers. Paidéia, Ribeirão Preto, v. 28, e2813, 2018. http:// dx.doi.org/10.1590/1982-4327e2813

BARDIN, Laurence. Análise de conteúdo. Lisboa: Edições 70 , 2008.

BEUMONT, Pierre Joseph Victor et al. Nutritional counseling in the treatment of bulimia. In: FICHTER, Manfred Maximilian. (Org.). Bulimia nervosa: basic research, diagnosis and therapy. Chichester, UK: John Wiley \& Sons, 1990. p. 309-19.
BIGHETTI, Felícia et al. Tradução e validação do Eating Attitudes Test em adolescentes do sexo feminino de Ribeirão Preto, São Paulo. Jornal Brasileiro de Psiquiatria, Rio de Janeiro, v. 53, n. 6, p. 339-346, 2004.

BRASIL. Ministério da Saúde. Secretaria de Atenção à Saúde. Departamento de Atenção Básica. Guia alimentar para a população brasileira. 2. ed. Brasília: Ministério da Saúde, 2014. Disponível em: http://bvsms.saude.gov.br/bvs/publicacoes/ guia_alimentar_populacao brasileira_2ed.pdf. Acesso em: 26 mar. 2015

CANESQUI, Ana Maria; GARCIA, Rosa Wanda Diez. (Org.). Antropologia e nutrição: um diálogo possível. Rio de Janeiro: FIOCRUZ, 2005.

CANGUILHEM, George. O normal e o patológico. Tradução de Maria Thereza Redig de Carvalho Barrocas. 6. ed. Rio de Janeiro: Forense Universitária, 2009.

COLUCCI, Regina Baptista. Organizações psicopatológicas nos distúrbios da inapetência. In: BRUNO, Cássia Aparecida Nuevo Barreto (Org.). Distúrbios alimentares: uma contribuição da psicanálise. Rio de Janeiro: Imago; 2010. p. 275-286.

DAMATTA, Roberto. O que faz o Brasil, Brasil? Rio de Janeiro: Rocco, 1986.

DIEZ-GARCIA, Rosa Wanda. Mudanças alimentares: implicações práticas, teóricas e metodológicas. In: DIEZGARCIA, Rosa Wanda; CERVATO-MANCUSO, Ana Maria; VANNUCCHI, Hélio. (Ed.). Nutrição e metabolismo: mudanças alimentares e educação nutricional. São Paulo: Guanabara Koogan, 2012. p. 3-17.

FERNANDES, Maria Helena. Transtornos alimentares: clínica psicanalítica. São Paulo: Casa do Psicólogo, 2006.

FISCHLER, Claude. Commensality, society and culture. Social Science Information, v. 50, n. 3-4, p. 528-548, 31 ago. 2011. https://doi.org/10.1177/0539018411413963

KLUMP, Kelly L. et al. Academy for eating disorders position paper: eating disorders are serious mental illnesses. The International Journal of Eating Disorders, New York, v. 42, n. 2, p. 97-103, 2009. https://doi.org/10.1002/eat.20589

LEONIDAS, Carolina; SANTOS, Manoel Antônio dos. Imagem corporal e hábitos alimentares na anorexia nervosa: uma revisão integrativa da literatura. Psicologia: Reflexão $e$ Crítica, Porto Alegre, v. 25, n. 3, p. 550-558, 2012. https://doi. org/10.1590/S0102-79722012000300015

LEONIDAS, Carolina; SANTOS, Manoel Antônio dos. Social support networks and eating disorders: an integrative review of the literature. Neuropsychiatric Disease and Treatment, Albany, Auckland, N. Z., v. 10, p. 915-927, May 2014. https:// doi.org/10.2147/NDT.S60735

LEONIDAS, Carolina; SANTOS, Manoel Antônio dos. Family relations in eating disorders: the Genogram as instrument of assessment. Ciência \& Saúde Coletiva, Rio de Janeiro, v. 20, n. 5, p. 1435-1447, 2015. https://doi.org/10.1590/141381232015205.07802014

LEONIDAS, Carolina; SANTOS, Manoel Antônio dos. Emotional meanings assigned to eating disorders: narratives of women with anorexia and bulimia nervosa. Universitas Psychologica, Bogotá, v. 16, n. 4, p. 189-201, 2017. http:// dx.doi.org/10.11144/javeriana.upsy16-4.emae. 
LEONIDAS, Carolina; SANTOS, Manoel Antônio dos. Symbiotic illusion and female identity construction in eating disorders: a psychoanalytical psychosomatics' perspective. Ágora: Estudos em Teoria Psicanalítica, Rio de Janeiro, v. 23, n. 1, p. 84-93, 2020. https://doi.org/10.1590/180944142020001010

LEONIDAS, Carolina et al. How do we target the factors that maintain anorexia nervosa? A behaviour change taxonomical analysis. International Review of Psychiatry, London, v. 31, n. 4, p. 403-410, 2019. https://doi.org/10.1080/09540261.2019.1 624509

MANOCHIO-PINA, Marina et al. Eating disorders: cultural model and consensus regarding food. Ecology of Food and Nutrition, New York, v. 54, n. 4, p. 418-435, 2015.

MEDEIROS Michelle; GALENO Alex. Olhares sobre a alimentação contemporânea: a gastro-anomia e os corpos de Botero. Revista de Nutrição, Campinas, v. 26, n. 4, p. 465-472, 2013. https://doi.org/10.1590/S1415-52732013000400008

MIRANDA, Maria Ramalho. O mundo objetal anoréxico e a violência bulímica em meninas adolescentes. Revista Brasileira de Psicanálise, São Paulo, v. 38, n. 2, p. 309-334, 2004.

NEVES, Tiago Iwasawa; PORCARO, Luiza Almeida; CURVO, Daniel Rangel. Saúde é colocar-se em risco: normatividade vital em Georges Canguilhem. Saúde e Sociedade, v. 26, n. 3, p. 626637, 2017. https://doi.org/10.1590/s0104-12902017170016

NITZKE, Susan; FREELAND-GRAVES, Jeanne; American Dietetic Association. Position of the American Dietetic Association: total diet approach to communicating food and nutrition information. Journal of the American Dietetic Association, Chicago, USA, v. 107, n. 7, p. 1224-1232, Jul. 2007. https://doi.org/10.1016/j.jada.2007.05.025

RIBEIRO, Rosane Pilot Pessa. Abordagem educacional dos transtornos alimentares. In: DIEZ-GARCIA, Rosa Wanda; CERVATO-MANCUSO, Ana Maria; VANNUCCHI, Hélio. (Ed.). Nutrição e metabolismo: mudanças alimentares e educação nutricional. São Paulo: Guanabara Koogan, 2012. p. 215-228.

ROMANELLI, Geraldo. O significado da alimentação na família: uma visão antropológica. Medicina, Ribeirão Preto, v. 39, n. 3, p. 333-339, 2006. https://doi.org/10.11606/issn.21767262.v39i3p333-339

SANTOS, Lígia Amparo da Silva. O corpo, o comer e a comida: um estudo sobre as práticas corporais e alimentares no mundo contemporâneo [online]. Salvador: EDUFBA, 2008. Disponível em: https://static.scielo.org/scielobooks/38m/pdf/ santos-9788523209087.pdf. Acesso em: 12 ago. 2019.

SANTOS, Manoel Antônio dos. Sofrimento e esperança: grupo de pacientes com anorexia e bulimia nervosas. Medicina, Ribeirão Preto, v. 39, n. 3, p. 386-402, jul./set. 2006. https:// doi.org/10.11606/issn.2176-7262.v39i3p386-402

SANTOS, Manoel Antônio dos; DIEZ-GARCIA, Rosa Wanda; LIOTINO-SANTOS, Maria. A sujeição aos padrões corporais culturalmente construídos em mulheres de baixa renda. Demetra: Alimentação, Nutrição \& Saúde, Rio de Janeiro, v. 10, n. 4, p. 761-774, 2015. https://doi.org/10.12957/ demetra.2015.16117

SANTOS, Manoel Antônio dos et al. Corpo, saúde e sociedade de consumo: a construção social do corpo saudável. Saúde \& Sociedade, São Paulo, v. 28, n. 3, p. 239-252, 2019. http:// dx.doi.org/10.1590/s0104-12902019170035

Fractal, Rev. Psicol., v. 32 - n. 2, p. 120-131, 2020
SATTER, Ellyn. Eating competence: definition and evidence for the Satter eating competence model. Journal of Nutrition Education and Behavior, Hamilton, USA, v. 39, 5 Suppl., p. S142-S153, sept./out. 2007.

SOUZA, Laura Vilela; SANTOS, Manoel Antônio dos. Proximidade afetiva no relacionamento profissional-paciente no tratamento dos transtornos alimentares. Psicologia em Estudo, Maringá, v. 18, n. 3, p. 395-405, 2013a. https://doi. org/10.1590/S1413-73722013000300002

SOUZA, Laura Vilela; SANTOS, Manoel Antônio dos. Quem é o especialista? Lugares ocupados por profissionais e pacientes no tratamento dos transtornos alimentares. Estudos de Psicologia, Natal, v. 18, n. 2, p. 259-267, 2013b. Disponível em: http://www.scielo.br/pdf/epsic/v18n2/v18n2a11.pdf. Acesso em: 20 nov. 2019.

VALDANHA, Élide Dezoti et al. A arte de nutrir vínculos: psicoterapia de grupo nos transtornos alimentares. Revista da SPAGESP, Ribeirão Preto, v. 15, n. 2, p. 94-108, dez. 2014. Disponível em http://pepsic.bvsalud.org/scielo.php?script=sci arttext\&pid=S1677-29702014000200008\&lng=pt\&nrm=iso. Acesso em: 20 maio 2020.

WORLD HEALTHY ORGANIZATION. Global database on body mass index. Report on WHO consultation on obesity. Geneve: WHO, 2006.

YIN, Robert K. Estudo de caso: planejamento e métodos. Porto Alegre: Bookman, 2001. 